\title{
The Prevalence of Sports-related Dental Injuries and the Rate of Awareness of Mouthguard Use among Child Athletes
}

\author{
(1) Farzad Mojarad1, (1) Maryam Farhadian², (1) Sima Torkaman¹ \\ ${ }^{1}$ Hamadan University of Medical Sciences Faculty of Dentistry, Department of Pediatric Dentistry, Hamadan, Iran \\ ${ }^{2}$ Hamadan University of Medical Sciences Faculty of Public Health, Department of Biostatistics, Hamadan, Iran
}

\begin{abstract}
Aim: Sport activities are among the most important causes of dental injuries. The prevalence of dental injuries is higher in children and in contact sports and the use of mouthguards can reduce their incidence. The goal of this study was to determine the frequency and type of dental injuries in child athletes and their parents' awareness regarding the use of mouthguards.

Materials and Methods: A cross-sectional study was conducted on child athletes aged 7-13 years. The questionnaires were completed by their parents. The questionnaire included questions on demographic data, type and history of sport activity, history of sports-related dental injuries, type of dental injury, awareness on mouthguards, type of mouthguard used and problems during its use. Data analysis was done using descriptive statistics and chi-square test. The level of significance was set at $p<0.05$.

Results: Three hundred fifty six child athletes with a mean age of $10.72 \pm 2.08$ years participated in the study. The prevalence of dental injuries during sport activity was $15.5 \%$ and was higher in boys ( $70.9 \%, 39$ of 55$)$ than in girls (29.09\%, 16 of 55) ( $p=0.008)$. The most commonly affected age was 12 years (38.2\%). The dental injuries rates were as follows: mobility (58\%), crown fracture (36.4\%) and avulsion (5.6\%). The rate of awareness of the mouthguard was $48.6 \%$, while the utilization rate was $23.9 \%$.

Conclusion: According to our results, the rate of dental injuries among boys and full contact sport players are high and the most common dental injury is mobility. The age and prevalence of dental injuries in young athletes in our study is not higher than has been reported in other countries. The provision of proper mouthguards and regular use of them may possibly reduce the occurrence of dental injuries during sport activity.
\end{abstract}

Keywords: Sports-related dental injuries, child athletes, mouthguard

\section{Introduction}

Sport plays an important role in a child's health (1-3). Sport activities are among the most important etiologic factors of traumatic dental injuries $(4,5)$. Given the daily advancements made in sport activities, the risk of dental injuries has risen among athletes (6). Sport activities contribute to one third of dental injuries (2). The rate of injury varies in different studies depending on the number, location, age and type of sport activity $(7,8)$. Contact sports and children are more vulnerable to these injuries (2,6,9-11). The most commonly prone age to sport-related dental injuries are between 7 and 11 years of age (12-14). The reason behind the increased incidence of dental injuries in children is their inability to detect injurious situations (15). Traumatic dental injuries not only occur during games, but also during training and exercise. The severity and 
frequency of contact are among the main causes of these injuries (16). There is an increased risk of dental injuries in contact sports such as boxing, football, basketball and hockey (3,16-18). The aftermath of these injuries can be the loss of teeth; root resorption and/or ankylosis may even occur in cases that have been treated. Subsequently, the patient may constantly undergo procedures such as repair, root treatment, implant, and the use of prostheses $(16,19)$. Dental injuries can have considerable social, psychological and economic impacts $(2,6)$. Treatment of dental injuries leads to absence from work and school (20). Sport dentistry deals with the prevention and treatment of activity/sportrelated dental injuries and oral diseases. This risk can be reduced by the use of a mouthguard (2,21-23). Mouthguards evenly distribute the force of the impact throughout the mouth and thus reduce the impact of injury $(2,18)$. Usually, they are made of ethyl vinyl acetate, given its non-toxic nature, elasticity, minimum humidity absorption, and easy construction $(2,24)$. When a mouthguard is not used, the risk of injury increases by 1.6-1.9 times. Multiple review studies have indicated that the use of a mouthguard reduces injury to both the soft and hard tissues (2). Although many studies have proven the positive and protective effect of mouthguard use, it is compulsory in only a few sports (such as: Boxing, martial arts, American football, ice hockey) $(6,25,26)$. Furthermore, there is no specific description of the type of mouthguard that is to be used (27). To our knowledge, data on the frequency of dental injuries and awareness of mouthguard use among 7 to 13-year-old child athletes in Hamadan (a city in west of Iran) is scarce. For this reason, this study was conducted.

\section{Materials and Methods}

This cross-sectional study was conducted on 356 children aged 7 to 13 years old practicing in organized sport activity in Hamadan's sport centers. This study was approved by the Ethics Committee of the Hamadan University of medical science (IR.UMSHA.REC.1397.728) and was conducted for a period of approximately 5 months from May2018 to October 2018. Since the athletes were aged less than 16 years, their parents had to complete the questionnaires.

This study was conducted by the parents' of child athletes who agreed to participate in the study, and provided informed consent. Children who were involved in different types of sports (more than one) $(n=26)$ and those who did not provide informed consent $(n=17)$ were excluded from the study.

The questionnaire was based on studies conducted earlier $(2,5,16,19,28)$, and confidentiality was guaranteed by keeping the participants' names anonymous. The questionnaire was comprised of three sections; the first part included questions on age, gender, type of sport activity and the duration of sport activity. The second part consisted of questions on sports dental injury and in cases of having a history of sports dental injuries; the time and type of injury, the time of arrival at a medical center, the type of medical center admitted to, returns to the clinic to examine the healing process (follow up) and the duration of follow-up visits. The third part included questions on the athletes' level of awareness regarding the mouthguard, mouthguard use, type of mouthguard used, difficulties faced during mouthguard use, presence or absence of a mouthguard at the time of injury, and the cause of injury if a mouthguard had been used.

Therefore, the types of sports were classified based on their extent of contact into the following groups: Non-contact groups: gymnastics; limited-contact sports: Volleyball, baseball; semi-contact sports: Karate, taekwondo; full-contact sports: Soccer, wrestling, boxing, judo (5,29-31). The time of treatment was classified into: Acute treatment; a few hours after the injury, sub-acute treatment; in the first 24 hours following injury, delayed treatment; more than 24 hours after injury, and no treatment (32).

\section{Statistical Analysis}

Statistical analysis was done with SPSS 21. Data were presented as numbers and percentage (\%). Data analysis was done using descriptive statistics and chi-square test. The level of significance was set at $p<0.05$.

\section{Results}

In total, 356 child athletes (age 7-13years) comprising 194 boys (54.5\%) and 162 girls (45.5\%) were included in the study. The mean age of the participants in the study was $10.72 \pm 2.08$ years.

The athlete's characteristics are shown in Table I.

Fifty-five (15.4\%) child athletes sustained dental injuries, 39 (70.9\%) were male, and 16 (29.09\%) were female participants $(p=0.008)$. The most commonly affected age was 12 years old (38.2\%). The prevalence of different injuries in different sports included in order: Handball (16.4\%); boxing (16.4\%); wrestling (14.5\%); baseball (12.7\%); soccer (10.9\%); judo (9.1\%); volleyball (9.1\%); taekwondo (5.5\%); gymnastics (3.6\%) and karate (1.8\%).

Among the 55 children with dental injuries, 49 of 55 had a history of sport activity of 1 to 5 years. Forty-eight children (87.3\%) sustained injuries during training, and 7 
$(12.7 \%)$ had sustained injuries during matches. Of these injured participants, (18\%) had not sought any treatment, 27 (49\%) had received acute treatment, 12 (22\%) had received sub-acute treatment, and $6(11 \%)$ had received delayed treatment. Twenty-nine (64.4\%) had visited public medical centers and 16 (35.6\%) had visited private dental clinics. The time of admission based on the type of injury is presented in Table II. Forty-six (83.6\%) of the injured children had revisited the dentist for an evaluation of the treatment process, and 9 (16.4\%) had no follow-up.

The types of dental injuries based on contact sports are presented in Table III. The most damage was seen in full- contact sports (67.27\%), and the most common injury was mobility (83.3\%).

There was a significant difference between the level of awareness regarding mouthguards and their utilization ( $p<0.001) ; 271(76.1 \%)$ children did not use a mouthguard, and 85 (23.9\%) did (Table IV).

Among the 271 children who did not use mouthguards, $45(16.6 \%)$ had sustained dental injuries, while only 10 $(11.8 \%)$ of those who used a mouthguard had sustained injuries. This difference was not statistically significant $(p=0.281)$. The association between mouthguard use and experience of dental injuries is presented in Table V. The

Table I. Characteristics of participants with or without dental injury

\begin{tabular}{|c|c|c|c|c|c|}
\hline \multicolumn{2}{|l|}{ Variable } & \multirow{2}{*}{$\begin{array}{l}\text { Total } \\
194(54.5) \\
162(45.5)\end{array}$} & \multirow{2}{*}{$\begin{array}{l}\text { Dental injuries } \\
\text { Non-injured } \mathbf{n}(\%)\end{array}$} & \multirow{2}{*}{$\begin{array}{l}\text { Injured } \\
\text { n (\%) } \\
39(70.9) \\
16(29.1)\end{array}$} & \multirow{2}{*}{$\begin{array}{l}\mathbf{p} \\
0.005\end{array}$} \\
\hline Gender & $\begin{array}{l}\text { Boys } \\
\text { Girls }\end{array}$ & & & & \\
\hline Age (mean $\pm S D)$ & $\begin{array}{l}\text { Boys } \\
\text { Girls }\end{array}$ & $\begin{array}{l}10.73 \pm 2.18 \\
10.71 \pm 1.95\end{array}$ & $\begin{array}{l}11.59(20.1) \\
10.63(9.9)\end{array}$ & $\begin{array}{l}10.51(79.9) \\
10.72(90.1)\end{array}$ & 0.008 \\
\hline Sport & $\begin{array}{l}\text { Soccer } \\
\text { Baseball } \\
\text { Gymnastics } \\
\text { Taekwondo } \\
\text { Karate } \\
\text { Wrestling } \\
\text { Judo } \\
\text { Handball } \\
\text { Boxing } \\
\text { Volleyball }\end{array}$ & $\begin{array}{l}43(12.1) \\
31(8.7) \\
34(9.6) \\
31(8.7) \\
34(9.6) \\
39(11.0) \\
28(7.9) \\
41(11.5) \\
39(11.0) \\
36(10.1)\end{array}$ & $\begin{array}{l}37(12.3) \\
24(8.0) \\
32(10.6) \\
28(9.3) \\
33(11.0) \\
31(10.3) \\
23(7.6) \\
32(10.6) \\
30(10.0) \\
31(10.3)\end{array}$ & $\begin{array}{l}6(10.9) \\
7(12.7) \\
2(3.6) \\
3(5.5) \\
1(1.8) \\
8(14.5) \\
5(9.1) \\
9(16.4) \\
9(16.4) \\
5(9.1)\end{array}$ & - \\
\hline Contact sport & $\begin{array}{l}\text { Non-contact sport } \\
\text { Limited-contact } \\
\text { Semi-contact sport } \\
\text { Full-contact sport }\end{array}$ & $\begin{array}{l}34(9.6) \\
67(18.8) \\
65(18.3) \\
190(53.4)\end{array}$ & $\begin{array}{l}32(10.6) \\
55(18.3) \\
61(20.3) \\
153(50.8)\end{array}$ & $\begin{array}{l}2(3.6) \\
12(21.8) \\
4(7.3) \\
37(67.3)\end{array}$ & 0.025 \\
\hline Experience (years) & $\begin{array}{l}>1 \text { to }<5 \\
\geq 5\end{array}$ & $\begin{array}{l}325(91.3) \\
31(8.7)\end{array}$ & $\begin{array}{l}276(91.7) \\
25(8.3)\end{array}$ & $\begin{array}{l}49(89.1) \\
6(10.9)\end{array}$ & - \\
\hline Training days per week & $\begin{array}{l}<3 \\
\geq 3\end{array}$ & $\begin{array}{l}153(43.0) \\
203(57.0)\end{array}$ & $\begin{array}{l}135(44.9) \\
166(55.1)\end{array}$ & $\begin{array}{l}18(32.7) \\
37(67.3)\end{array}$ & 0.063 \\
\hline Training hours per day & $\begin{array}{l}\leq 3 \\
>3 \text { to }<5 \\
\geq 5\end{array}$ & $\begin{array}{l}217(61.0) \\
109(30.6) \\
29(8.1)\end{array}$ & $\begin{array}{l}188(62.7) \\
87(29.0) \\
25(8.3)\end{array}$ & $\begin{array}{l}29(52.7) \\
22(40.0) \\
4(7.3)\end{array}$ & - \\
\hline \multicolumn{2}{|l|}{ Total } & 356 & 301 & 55 & - \\
\hline
\end{tabular}

Table II. Time of treatment and dental injury

\begin{tabular}{|l|l|l|l|l|}
\hline \multirow{2}{*}{ Type of injury } & \multicolumn{2}{|l|}{ Time of treatment } \\
\cline { 2 - 5 } & $\begin{array}{l}\text { No treatment } \\
\mathbf{n}(\%)\end{array}$ & $\begin{array}{l}\text { Acute treatment } \\
\mathbf{n}(\%)\end{array}$ & $\begin{array}{l}\text { Sub-acute treatment } \\
\mathbf{n}(\%)\end{array}$ & $\begin{array}{l}\text { Delayed treatment } \\
\mathbf{n}(\%)\end{array}$ \\
\hline Crown fracture & $5(50.0)$ & $7(26)$ & $4(33.3)$ & $4(66.7)$ \\
\hline Mobility & $4(40.0)$ & $18(66.6)$ & $8(66.7)$ & $2(33.3)$ \\
\hline Avulsion & $1(10.0)$ & $2(7.4)$ & $0(0.0)$ & $0(0.0)$ \\
\hline
\end{tabular}


rate of using a mouthguard in sports where they are mandatory is presented in Figure 1. The association between the experience of dental injuries and mouthguard use in sports where they are mandatory is presented in Table VI.

The most common type of mouthguard used was the boil and bite type (67\%); the next most common was the one prepared by the dentist (custom fabricated) $(28.4 \%) ; 4.6 \%$ of the parents were unaware of the type of mouthguard their children used. The problems children had while using the mouthguard were as follows: difficulty breathing; pain and discomfort in the mouth; and lack of beauty. Of those children who had sustained injuries, 45 had not used a mouthguard and 10 had used one. In the parents' opinions, the reason behind the injury in spite of mouthguard use was its lack of suitability (58.8\%) and the type used (41.2\%).

\section{Discussion}

Sport causes dental and facial injuries, which can be prevented through adequate training and the use of protective tools (21). Based on this cross-sectional study, the prevalence of dental injury in this age group was $15.4 \%$. Few studies have dealt with the prevalence of dental injuries in child athletes.

Farcasiu et al. (6) reported this figure to be $14.36 \%$ in children aged $10.24 \pm 1.97$ years. Galic et al. (33) reported this prevalence to be $13.5 \%$ in children from four contact sports and aged $12.9 \pm 3.2$ years. Tsuchiya et al. (5) reported a rate of $13.3 \%$ in children with a mean age of 11 years (33). The aforementioned studies' findings are close to ours. In a systematic review conducted by Azami-Aghdas et al. (34), the prevalence of dental injuries among children was reported to be $17.5 \%$. Ozbay et al. (28) observed rate of injury in $12 \pm 1.6$-year-old children was $19.3 \%$, a figure higher than ours, which may be explained by examining the injury as a whole, the athletes' age and the type of sports played.

Between 6 to 12 years of age, the continuous development of power movements becomes dominant, and the period of development of delicate motor skills begins (35). Children are more prone to dental injuries between the ages of 7 and 11 (36). Furthermore, the risk of injury increases with age as the duration of exercise lengthens (37). In our study, the most commonly injured age was the age of 12 years $(38.2 \%)$, which almost the same as those of studies conduct by Naidoo et al. (38), Ozbay et al. (11), and Kececi et al. (19), Naidoo et al. (38) also studied the occurrence of dental injuries in school-going children aged 11 to 13 years, and found that the most commonly affected age was 12 years. Ozbay et al. (11) made a similar observation. Kececi et al. (19) reported that the risk of injuries was greater at younger ages $(<12$ years).

In line with other studies, the prevalence of dental injuries was reported to be higher among boys than among girls $(8,28,39,40)$. This may be attributed to several factors, such as, internal factors like biological differences, bodily strength, weight and psychological traits, and environmental factors, such as play management - including the coaching style (5).

In our study, most injuries were sustained during training (86.8\%); Ozbay et al. (11) have also mentioned the occurrence of dental injuries during matches.

At younger ages, the density of the alveolar bone is lower, thus, luxation is common. Aging is associated with an increase in bone density. Moreover, the lower crown/root ratio raises the possibility of crown fractures (41). The most common dental injury in our study was mobility, which is due to the lower alveolar bone density and root immaturity. Rouhani et al. (16) examined dental injuries among young athletes (20 to 30 year-olds) and also observed that the most common dental injury was luxation; despite the difference in the age group, the finding was similar to ours. Galic, however, has reported avulsion as the most common injury (33). Kececi et al. (19) observed that crown fractures were the most common injury. Likewise, Farcasiu et al. (6) reported enamel fractures as the most frequently occurring

Table IV. Relation between awareness and use of a mouthguard

\begin{tabular}{|l|l|l|l|}
\hline \multirow{2}{*}{ Awareness } & \multicolumn{2}{|l|}{ Using mouthguard } & \multirow{2}{*}{ p } \\
\cline { 2 - 3 } & Yes, n (\%) & No, n (\%) & \\
\hline Yes & $74(87.1)$ & $99(36.5)$ & 0.001 \\
\hline No & $11(12.9 \%)$ & $172(63.5)$ & \\
\hline
\end{tabular}

Table III. Type of dental injury with respect to level of contact in sport

\begin{tabular}{|l|l|l|l|l|l|}
\hline \multirow{2}{*}{ Type of injury } & \multirow{5}{|l|}{ Contact sport } \\
\cline { 3 - 7 } & Total & $\begin{array}{l}\text { Non-contact } \\
\text { sport n (\%) }\end{array}$ & $\begin{array}{l}\text { Limited-contact } \\
\text { sport n (\%) }\end{array}$ & $\begin{array}{l}\text { Semi-contact } \\
\text { sport n (\%) }\end{array}$ & $\begin{array}{l}\text { Full-contact sport } \\
\text { n (\%) }\end{array}$ \\
\hline Crown fracture & $20(36.4)$ & $1(5.6)$ & $6(33.3)$ & $3(16.7)$ & $10(27.0)$ \\
\hline Mobility & $32(58)$ & $1(3.1)$ & $5(15.6)$ & $1(3.1)$ & $25(83.3)$ \\
\hline Avulsion & $3(5.6)$ & 0 & $1(33.3$ & 0 & $2(6.7)$ \\
\hline
\end{tabular}




\begin{tabular}{|l|l|l|l|}
\hline \multicolumn{3}{|l|}{ Table V. Relation between mouthguard use and dental injures } \\
\hline \multirow{2}{*}{$\begin{array}{l}\text { Using } \\
\text { mouthguard }\end{array}$} & Dental injuries & p \\
\cline { 2 - 3 } & Non injured, $\mathbf{n}(\%)$ & Injured, $\mathbf{n}(\%)$ & \\
\hline Yes & $75(88.2)$ & $10(11.8)$ & 0.281 \\
\hline No & $226(83.4)$ & $45(16.6)$ & \\
\hline
\end{tabular}

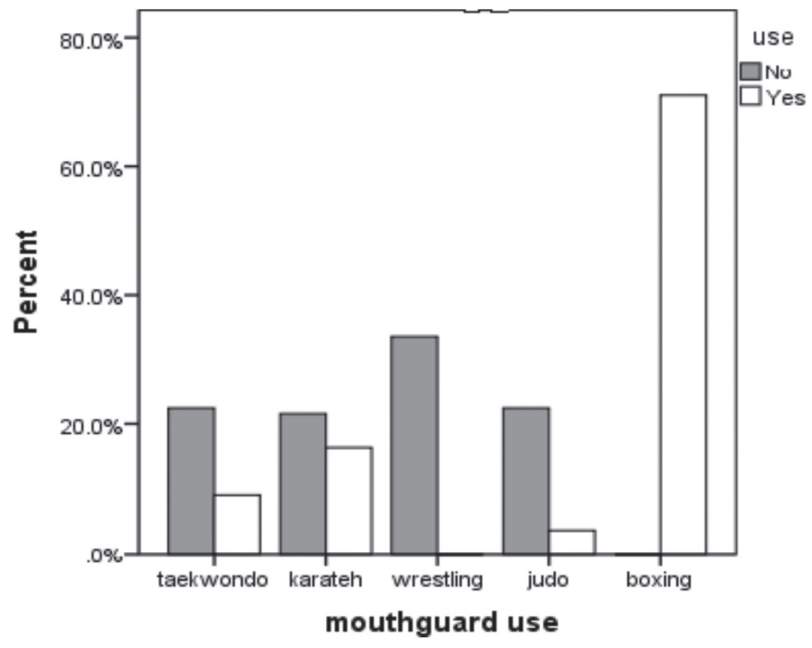

Figure 1. Rate of using mouthguards in sports where they are mandatory

Table VI. Relation between dental injuries and use of mouthguards in sports where they are mandatory and other sports

\begin{tabular}{|c|c|c|c|c|}
\hline \multirow{2}{*}{ Type of sport } & \multirow{2}{*}{$\begin{array}{l}\text { Dental } \\
\text { injures }\end{array}$} & \multicolumn{2}{|c|}{ Using mouthguard } & \multirow{2}{*}{ Total } \\
\hline & & No n (\%) & Yes n (\%) & \\
\hline \multirow{2}{*}{ Boxing } & No & 0 & $30(76.92)$ & \multirow[t]{2}{*}{39} \\
\hline & Yes & 0 & $9(23.07)$ & \\
\hline \multirow{2}{*}{ Judo } & No & $22(78.57)$ & $1(3.57)$ & \multirow{2}{*}{28} \\
\hline & Yes & $4(14.28)$ & $1(3.57)$ & \\
\hline \multirow{2}{*}{ Wrestling } & No & $31(79.48)$ & 0 & \multirow{2}{*}{39} \\
\hline & Yes & $8(20.51)$ & 0 & \\
\hline \multirow{2}{*}{ Karate } & No & $24(70.58)$ & $9(26.47)$ & \multirow{2}{*}{34} \\
\hline & Yes & $1(2.94)$ & 0 & \\
\hline \multirow{2}{*}{ Taekwondo } & No & $23(74.19)$ & $5(16.12)$ & \multirow{2}{*}{31} \\
\hline & Yes & 3 & 0 & \\
\hline Other sports & No & 126 & 30 & 185 \\
\hline
\end{tabular}

dental injuries. These differences may be attributed to the type of dental system, bone density, type and extent of force applied, and type of sport.

The greater the velocity and contact, the greater the sport injury $(2,6)$. In our study, dental injuries more frequently occurred in full-contact sports, a finding similar to those reached by Rouhani et al. (16) and Glendor (8) but contrary to Tsuchiya et al. (5) results, who did not find a significant association between the type of contact sport and the occurrence of injury. Raising awareness, the existence of rules mandating the use of mouthguards in high-risk sports and encouraging athletes to regularly use mouthguards can reduce the rate of injury.

Reducing the episodes and severity of sport-related dental injuries is the greatest goal of many sports; by using protective gear, we can achieve this goal to some extent. Unfortunately, mouthguard use is not mandatory in many high-risk sports including basketball and soccer (42). In our study, although $48.6 \%$ of parents were aware of mouthguards, only $42.8 \%$ of their children used them. This finding is similar to the results of the studies by Dursun et al. (42), Rouhani et al. (16) and Tiwari et al. (21), wherein the use of mouthguards was limited in spite of athletes being aware of them. Parents should be informed of the risks of dental injuries and their aftermaths and the advantages of using suitable mouthguards (2). Many studies have shown the protective effect of mouthguard use in reducing injury $(28,42-45)$, the provision of proper mouthguards may possibly reduce the occurrence of TDI. However, there is still insufficient evidence that planned intervention is effective in reducing the prevalence or incidence of sports-related injuries to the mouth and face, and much remains to be elucidated regarding the attitude toward and effective use of protective equipment (46). Although the use of mouthguards had reduced injury, the difference was statistically insignificant when compared to the group that had not used mouthguards, which may be due to the type of mouthguard used, a lack of awareness regarding its replacement, structural changes and reduced efficacy over time, and the avoidance of its continuous use throughout sports such as during training. Sport coaches and dentists can play a positive role in raising awareness about and the use of mouthguards in athletes (21). Athletes need to be informed about the type of mouthguard, their replacement time, and the role of their thickness in preventing injury, as thickness plays a major role in protecting teeth and the surrounding tissues (47).

The participants of our study mostly used the boil and bite type of mouthguard, similar to O'Malley et al. (2) study, wherein two thirds of parents had reported their children using this type of mouthguard. These mouthguards are commonly used by children. Given the continuous oral changes in mix dentition ages, there is a possibility for remolding. Nevertheless, this type of mouthguard's fit may decline over time, which may limit its efficacy (26). Thus, custom mouthguards are used by $4 \%$ of children, 
and policies should be regulated to make them available and raise awareness on their usage (2). Our participants experienced difficulties such as, difficulty breathing, feelings of pain and discomfort and lack of beauty, which were similar to the problems reported by Boffano et al. (48), Ranalli (49) and Duddy et al. (50). In addition to the aforementioned problems, they reported difficulty speaking and changes in the mouthguard during its utilization, all of which may be reduced by using the custom type $(50,51)$.

\section{Study Limitations}

The limitation of our study was some parents' poor cooperation in the timely completion and handing over of the questionnaires. The use of electronic questionnaires can alleviate this problem to some extent.

\section{Conclusion}

According to our study, dental injuries were relatively high among boys and full contact sport players. The most commonly injured age and the prevalence of dental injuries in child athletes are similar to other studies conducted. Provision of proper mouthguards may reduce the occurrence of dental injuries during sport activity. Educational programs to increase awareness, improve knowledge, and promote the use of proper mouthguards with young athletes and their parents are needed.

\section{Acknowledgements}

We would like express our appreciation to all participants of this study for their co-operation in answering and returning the questionnaires.

\section{Ethics}

Ethics Committee Approval: This study was approved by the Ethics Committee of the Hamadan University of medical science (IR.UMSHA.REC.1397.728).

Informed Consent: This study was conducted by the parents' of child athletes who agreed to participate in the study, and provided informed consent.

Peer-review: Externally peer-reviewed.

\section{Authorship Contributions}

Surgical and Medical Practices: F.M., M.F., S.T., Concept: F.M., M.F., S.T., Design: F.M., M.F., S.T., Data Collection or Processing: F.M., M.F., S.T., Analysis or Interpretation: F.M., M.F., S.T., Literature Search: F.M., M.F., S.T., Writing: S.T.

Conflict of Interest: No conflict of interest was declared by the authors.
Financial Disclosure: The authors declared that this study received no financial support.

\section{References}

1. Goswami N, Gandhi A, Patel P, Dikshit R. An evaluation of knowledge, attitude and practices about prescribing fixed dose combinations among resident doctors. Perspectives in clinical research 2013; 4:130-5.

2. O'Malley M, Evans DS, Hewson A, Owens J. Mouthguard use and dental injury in sport: a questionnaire study of national school children in the west of Ireland. Journal of the Irish Dental Association 2012; 58:205-11.

3. Al-Arfaj I, Al-Shammari A, Al-Subai T, et al. The knowledge, attitude and practices of male sports participants to sportsrelated dental trauma in Khobar and Dammam, Saudi Arabia - A pilot survey. The Saudi dental journal 2016; 28:136-41.

4. Gassner R, Bösch R, Tuli T, Emshoff R. Prevalence of dental trauma in 6000 patients with facial injuries: implications for prevention. Oral Surgery, Oral Medicine, Oral Pathology, Oral Radiology, and Endodontology 1999; 87:27-33.

5. Tsuchiya S, Tsuchiya M, Momma H, et al. Factors associated with sports-related dental injuries among young athletes: a crosssectional study in Miyagi prefecture. BMC oral health 2017; 17:168.

6. Farcașiu C, Farcașiu A-T, Munteanu A, Stanciu I, Luca R. Sports related dental trauma in mixed dentition in Bucharest. Romanian Journal of Oral Rehabilitation. 2012; 4:59.

7. Kumamoto D, Maeda Y. Global trends and epidemiology of sports injuries. I Pediatr Dent Care 2005; 11:15.

8. Glendor U. Aetiology and risk factors related to traumatic dental injuries-a review of the literature. Dental Traumatology 2009; 25:19-31.

9. Cortes MI, Marcenes W, Sheiham A. Impact of traumatic injuries to the permanent teeth on the oral health-related quality of life in 12-14-year-old children. Community dentistry and oral epidemiology 2002; 30:193-8.

10. Ferrari $\mathrm{CH}$, De Medeiros JMF. Dental trauma and level of information: mouthguard use in different contact sports. Dental Traumatology 2002; 18:144-7.

11. Ozbay G, Bakkal M, Abbasoglu Z, Demirel S, Kargul B, Welbury $R$. Incidence and prevention of traumatic injuries in paediatric handball players in Istanbul, Turkey. European Archives of Paediatric Dentistry 2013; 14:41-5.

12. Tesini D, Soporowski N. Epidemiology of orofacial sports-related injuries. Dental clinics of North America 2000 ;44:1-18.

13. ADA Council on Access, Prevention and Interprofessional Relations; ADA Council on Scientific Affairs. Using mouthguards to reduce the incidence and severity of sports-related oral injuries. The Journal of the American Dental Association 2006; 137:1712-20.

14. Stewart GB, Shields B), Fields S, Dawn Comstock R, Smith GA. Consumer products and activities associated with dental injuries to children treated in United States emergency departments, 1990-2003. Dental traumatology 2009; 25:399-405.

15. Borssén E, Källestal C, Holm AK. Treatment time of traumatic dental injuries in a cohort of 16-year-olds in northern Sweden. Acta odontologica Scandinavica 2002; 60:265-70.

16. Rouhani A, Ghoddusi I, Rahmandost MR, Akbari M. Prevalence of traumatic dental injuries among contact sport practitioners 
in Northeast of Iran in 2012. Journal of Dental Materials and Techniques 2016; 5:82-5.

17. Kumamoto $D$, Maeda Y. A literature review of sports-related orofacial trauma. General dentistry 2004; 52:270-80; quiz 81.

18. Ranalli DN. Prevention of sports-related traumatic dental injuries. Dental clinics of North America 2000; 44:35-51, v-vi.

19. Keçeci $A D$, Eroğlu $E$, Baydar ML. Dental trauma incidence and mouthguard use in elite athletes in Turkey. Dental Traumatology. 2005; 21:76-9.

20. Adirim TA, Cheng TL. Overview of injuries in the young athlete. Sports medicine 2003; 33:75-81.

21. Tiwari V, Saxena V, Tiwari U, Singh A, Jain M, Goud S. Dental trauma and mouthguard awareness and use among contact and noncontact athletes in central India. Journal of oral science 2014; 56:239-43.

22. Tulunoglu I, Özbek M. Oral trauma, mouthguard awareness, and use in two contact sports in Turkey. Dental Traumatology 2006; 22:242-6.

23. Aljohani YR, Alfaifi KH, Redwan SK, Sabbahi DA, Zahran MH. Dental injuries in taekwondo athletes practicing in Saudi Arabia. Saudi medical journal 2017; 38:1143-7.

24. Westerman B, Stringfellow P, Eccleston I. Beneficial effects of air inclusions on the performance of ethylene vinyl acetate (EVA) mouthguard material. British journal of sports medicine 2002; 36:51-3.

25. Knapik J), Marshall SW, Lee RB, et al. Mouthguards in sport activities history, physical properties and injury prevention effectiveness. Sports medicine 2007; 37:117-44.

26. American Academy of Pediatric Denstistry Clinical Affairs Committee; American Academy of Pediatric Dentistry Council on Clinical Affairs. Policy on prevention of sports-related orofacial injuries. Pediatric dentistry 2005; 27(7 Suppl):45.

27. Mills SC. Mandatory mouthguard rules for high school athletes in the United States. Ceneral dentistry 2015; 63:35-40.

28. Ozbay G, Bakkal M, Abbasoglu Z, Demirel S, Kargul B, Welbury $\mathrm{R}$. Incidence and prevention of traumatic injuries in paediatric handball players in Istanbul, Turkey. European archives of paediatric dentistry 2013; 14:41-5.

29. Mintah JK, Huddleston S, Doody SG. Justifications of aggressive behavior in contact and semicontact sports. Journal of Applied Social Psychology 1999; 29:597-605.

30. Gartland S, Malik M, Lovell M. Injury and injury rates in Muay Thai kick boxing. British journal of sports medicine 2001; 35:308-13.

31. Sohrabi F, Atashak S, Aliloo M. Psychological profile of athletes in contact and non-contact sports. Middle-East Journal of Scientific Research 2011; 9:638-44.

32. Andreasen I, Andreasen F, Skeie A, Hjørting-Hansen E, Schwartz O. Effect of treatment delay upon pulp and periodontal healing of traumatic dental injuries-a review article. Dental traumatology 2002; 18:116-28.

33. Galic T, Kuncic D, Pericic TP, et al. Knowledge and attitudes about sports-related dental injuries and mouthguard use in young athletes in four different contact sports-water polo, karate, taekwondo and handball. Dental traumatology 2018; 34:175-81.

34. Azami-Aghdash S, Azar FE, Azar FP, et al. Prevalence, etiology, and types of dental trauma in children and adolescents: systematic review and meta-analysis. Medical journal of the Islamic Republic of Iran 2015; 29:234.

35. Nowak Al, Skotowski MC, Widmer R, Strate J, Cugini M. A practice based evaluation of a range of children's manual toothbrushes: safety and acceptance. Compendium of continuing education in dentistry 2002; 23(3 Suppl 2):17-24.

36. Newsome P, Tran D, Cooke M. The role of the mouthguard in the prevention of sports-related dental injuries: a review. International Journal of Paediatric Dentistry 2001; 11:396-404.

37. Muller-Bolla M, Lupi-Pegurier L, Pedeutour P, Bolla M. Orofacial trauma and rugby in France: epidemiological survey. Dental Traumatology 2003; 19:183-92.

38. Naidoo S, Sheiham A, Tsakos G. Traumatic dental injuries of permanent incisors in 11-to 13-year-old South African schoolchildren. Dental traumatology 2009; 25:224-8.

39. Goettems ML, Schuch HS, Hallal PC, Torriani DD, Demarco FF. Nutritional status and physical activity level as risk factor for traumatic dental injuries occurrence: a systematic review. Dental Traumatology 2014; 30:251-8.

40. Welch C, Thomson M, Kennedy R. ACC claims for sports-related dental trauma from 1999 to 2008: a retrospective analysis. New Zealand Dental Journal 2010; 106:137-42.

41. Järvinen S. Incisal overjet and traumatic injuries to upper permanent incisors: A retrospective study. Acta Odontologica Scandinavica $1978 ; 36: 359-62$

42. Dursun E, Ilarslan YD, Ozgul O, Donmez G. Prevalence of dental trauma and mouthguard awareness among weekend warrior soccer players. J Oral Sci 2015; 57:191-4.

43. Tanaka $Y$, Maeda $Y$, Yang TC, Ando T, Tauchi $Y$, Miyanaga $H$. Prevention of orofacial injury via the use of mouthguards among young male rugby players. International journal of sports medicine $2015 ; 36: 254-61$.

44. Frontera RR, Zanin L, Ambrosano GMB, Flório FM. Orofacial trauma in Brazilian basketball players and level of information concerning trauma and mouthguards. Dental traumatology 2011; 27:208-16.

45. Yeşil Duymuş Z, Gungor $H$. Use of mouthguard rates among university athletes during sport activities in Erzurum, Turkey. Dental traumatology 2009; 25:318-22.

46. Billings RJ, Berkowitz RJ, Watson G. Teeth. Pediatrics 2004; 113(Supplement 3):1120-7.

47. Guevara PH, Hondrum SO, Reichl RB. A comparison of commercially available mouthguards and a custom mouthguard. Gen Dent 2001; 49:402-6.

48. Boffano P, Boffano M, Gallesio C, Roccia F, Cignetti R, Piana R. Rugby athletes' awareness and compliance in the use of mouthguards in the North West of Italy. Dental Traumatol 2012; 28:210-3.

49. Ranalli DN. Sports dentistry and dental traumatology. Dental Traumatology 2002; 18:231-6.

50. Duddy FA, Weissman J, Lee Sr RA, Paranjpe A, Johnson JD, Cohenca $\mathrm{N}$. Influence of different types of mouthguards on strength and performance of collegiate athletes: a controlled-randomized trial. Dental traumatology 2012; 28:263-7.

51. Boffano P, Boffano M, Gallesio C, Roccia F, Cignetti R, Piana R. Rugby athletes' awareness and compliance in the use of mouthguards in the North West of Italy. Dental Traumatology 2012; 28:210-3. 